\title{
Natural multi-occurrence of mycotoxins in rice from Niger State, Nigeria
}

\author{
Hussaini Anthony Makun • Michael Francis Dutton • \\ Patrick Berka Njobeh • Mulunda Mwanza • \\ Adamu Y. Kabiru
}

Received: 22 May 2010/Revised: 16 November 2010 /Accepted: 17 November 2010/Published online: 12 January 2011

(C) The Author(s) 2010. This article is published with open access at Springerlink.com

\begin{abstract}
Twenty-one rice samples from field (ten), store (six) and market (five) from the traditional rice-growing areas of Niger State, Nigeria were analysed for aflatoxins (AFs), ochratoxin A (OTA), zearalenone (ZEA), deoxynivalenol (DON), fumonisin $\mathrm{B}_{1}\left(\mathrm{FB}_{1}\right)$ and $\mathrm{B}_{2}\left(\mathrm{FB}_{2}\right)$, and patulin (PAT) by thin-layer chromatography (TLC) and high-performance liquid chromatography (HPLC) respectively. T-2 toxin was determined using TLC only. AFs were detected in all samples, at total AF concentrations of 28 $372 \mu \mathrm{g} / \mathrm{kg}$. OTA was found in $66.7 \%$ of the samples, also at high concentrations $(134-341 \mu \mathrm{g} / \mathrm{kg})$ that have to be considered as critical levels in aspects of nephrotoxicity. ZEA (53.4\%), DON (23.8), $\mathrm{FB}_{1}(14.3 \%)$ and $\mathrm{FB}_{2}(4.8 \%)$ were also found in rice, although at relatively low levels. T2 toxin was qualitatively detected by TLC in only one sample. Co-contamination with AFs, OTA, and ZEA was very common, and up to five mycotoxins were detected in a single sample. The high AF and OTA levels as found in rice in this study are regarded as unsafe, and multi-occurrences of mycotoxins in the rice samples with possible additive or synergistic toxic effects in consumers raise concern with respect to public health.
\end{abstract}

H. A. Makun $(\bowtie) \cdot$ A. Y. Kabiru

Department of Biochemistry, Federal University of Technology, P.M.B 65,

Minna, Niger State, Nigeria

e-mail: hussainimakun@yahoo.com

M. F. Dutton · P. B. Njobeh • M. Mwanza

Food, Environment and Health Research Group, Faculty of Health

Science, University of Johannesburg, Doornfontein Campus,

2028 Gauteng, P.O. Box 17011, South Africa
Keywords Mycotoxins · Co-occurrence · Rice · Chromatography $\cdot$ Nigeria

\section{Introduction}

Fungi are ubiquitous plant pathogens and so are major spoilage agents of foods and feedstuffs. The infection of plants by various fungi not only results in reduction in crop yield and quality, with significant economic losses, but also contamination of grains with poisonous fungal secondary metabolites called mycotoxins. The ingestion of such mycotoxin-contaminated grains by animals and human beings has enormous public health significance, because these toxins are capable of causing diseases in man and animals (Bhat and Vasanthi 2003). Of greatest concern is the relevance of these toxins in human hepatoma and oesophageal cancer (Shephard 2008).

There are hundreds of mycotoxins found in foods, but those that pose the greatest risk to human and animal health are aflatoxins (AFs), trichothecenes [e.g. deoxynivalenol (DON), T-2 toxin], fumonisins (FBs), zearalenone (ZEA), patulin (PAT) and ochratoxin A (OTA) (CAST 2003). The $\mathrm{AFs}$, especially the most potent, $\mathrm{AFB}_{1}$, are primarily known hepatotoxins and hepatocarcinogens, which were the cause of death of 215 people in Kenya who consumed highly AF-contaminated maize meals in 2004 (CDC 2004). Trichothecenes are a group of about 150 related compounds that are protein inhibitors with consequent immunosuppressive effects, causing severe damage to the digestive tract and death due to intestinal haemorrhage. The commonest trichothecenes are DON and T-2 toxin (Sudakin 2003). Fumosins, especially fumonisin $\mathrm{B}_{1}\left(\mathrm{FB}_{1}\right)$ cause liver and kidney cancer, and neural tube defects in rodents, leukoencephalomalacia in horses and pulmonary oedema in pigs 
(Dutton 1996). Of major concern is the association of $\mathrm{FB}_{1}$ with elevated incidence of human oesphageal cancer in parts of South Africa, North Eastern Iran and China, upper gastrointestinal tract cancer in Northern Italy (Chu and $\mathrm{Li}$ 1994; Rheeder et al. 1992; Sydenham et al. 1990) and neural tube defects in human babies (Hendricks 1999). ZEA, an oestrogenic toxin that causes infertility in animals, is associated with outbreaks of precocious pubertal changes in children in Puerto Rico, and has been suggested to have a possible involvement in human cervical cancer (Zinedine et al. 2007). OTA causes kidney and liver impairment in animals (especially pigs) and man (Hussein and Brasel 2001).

The established presence of these major mycotoxins and the fungi that produce them in rice in several parts of the world (Reddy et al. 2008) demonstrates that cereal supports growth of fungi and mycotoxin production. Apart from the suitability for fungal development and mycotoxin production, rice is highly cultivated and consumed worldwide and this makes it one of the most important principal sources of mycotoxins to human beings and animals in the world. It is the world's most extensively cultivated crop after wheat and a staple food of nearly $50 \%$ of the total world population (FAO 2002). In Nigeria, rice is the sixth most cultivated crop after sorghum, millet, cowpea, cassava and yam. According to the FAO Statistics Division, Nigeria produced about 4.7 million tones of paddy rice in 2007, making it the second largest producer of rice in Africa after Egypt (FAO 2008). In spite of this amount produced, Nigeria imported about 1.6 million tones of rice (USDA 2008b) and consumed about 4.9 million tones in 2008 (USDA 2008a), making it the third world's major rice importing country after Iran and Philippines. The deficit in the national annual demand for rice is an indication of a cereal that is highly consumed in the country. Rice is grown primarily for the market in Nigeria (Erenstein and Lancon 2003) and therefore has a wider distribution and hence a more likely source of mycotoxins than most other crops.

Niger State is the traditional rice growing area of Nigeria with the second highest rice yield of the six major riceproducing states in the country (Erenstein and Lancon 2003). It contributes about $16 \%$ of the national rice produce of the country (Ezedinma 2005). It is a generally hot and humid (average annual temperature of $31.7^{\circ} \mathrm{C}$ and average humidity of $51.6 \%$ ) middle-belt state of Nigeria. These climatic conditions are very favourable for fungal growth and mycotoxin production in foods and feeds. In spite of its strategic position as a national food basket, there is a general paucity of information on mycotoxins, particularly on rice, in the state and indeed in the whole country, except for a few reports (Makun et al. 2007, 2009). The present study is, therefore, a survey for the major mycotoxins (AFs $\mathrm{B}_{1}, \mathrm{~B}_{2}, \mathrm{G}_{1}$ and $\mathrm{G}_{2}$, OTA, ZEA, FBs $\mathrm{B}_{1}$, DON, T-2 toxin and PAT) in rice grown in Niger State. The generated incidence data and profile of mycotoxins of the widely distributed and highly consumed staple, rice, grown in a leading food-producing state of Nigeria, from this study was aimed at establishing the quality of Nigerian grown rice. This study also aimed to elucidate the types of animal and human diseases expected from our diets and the extent of risk to mycotoxicoses.

\section{Materials and methods}

\section{Materials}

All reagents used were of analytical grade and the solvents used for HPLC were of HPLC grade obtained from Merck or Sigma unless otherwise stated.

\section{HPLC equipment}

HPLC analysis was performed using a Shimadzu system (Kyoto, Japan), consisting of liquid chromatograph LC 20A fitted to degasser DGU 20A3, auto sampler (injection) SIL 20A, communications bus module CBM 20A, column oven CTO 20A, photodiode array detector SPD M20A and fluorescence detector RF 10AXL, all connected to a gigabyte computer with Intel Core DUO with Microsoft XP. It was fitted with a Symmetry column $(250 \times 4.6 \mathrm{~mm}$ i.d., $5 \mu \mathrm{m}$ particle size) with a Waters Sentry guard column (Waters, Milford, USA).

2. SAX cartridge (ANATECH, Gauteng, South Africa)

3. Mycotoxin standards

AFs $B_{1}, B_{2}, G_{1}$ and $G_{2}$, OTA, ZEA, DON, T-2 toxin and PAT standards were obtained from Sigma, St. Louis, Mo., USA. FBs $\mathrm{B}_{1}, \mathrm{~B}_{2}$ and $\mathrm{B}_{3}$ were purchased from PROMEC, MRC, South Africa.

\section{Sampling}

Twenty-one rice samples from the fields (ten), storage facilities (six) and markets (five) were randomly collected through donations and purchases in December 2008 from 21 villages in the traditional rice growing area of Niger State. The samples (about $0.5 \mathrm{~kg}$ each) were put in sealed plastic bottles and transported to our laboratory in South Africa where they were stored in the deep freezer at $-20^{\circ} \mathrm{C}$ until used for analysis.

Mycotoxin extraction and clean-up of rice samples

A multi-mycotoxin extraction method (multi-mycotoxin screen) devised by Patterson and Roberts (1979) was used for extractions of all the AFs, ZEA, OTA, DON, T-2 toxin, 
and PAT. The toxins were extracted into aqueous acetonitrile containing potassium chloride and the toxins further extracted with dichloromethane with added sodium bicarbonate to obtain a neutral $(\mathrm{N})$ fraction and after reacidification to obtain an acid (A) fraction. The $\mathrm{N}$ fraction was subjected to dialysis against $30 \%$ aqueous acetone overnight and then back-extracted into dichloromethane. The two fractions were evaporated and dried under a nitrogen gas stream and stored in sealed vials. A different extraction method to that for the other mycotoxins was used for FBs. Extraction of FBs and clean-up were done according to the method of Sydenham et al. (1992) without modification.

Thin-layer chromatographic technique

The mycotoxins in the neutral and acid fractions were detected by a two-dimensional thin-layer chromatographic technique of Patterson and Roberts (1979) without modification. The neutral fractions were subjected to twodimensional chromatography for AFs, ZEA, DON, T-2 toxins and PAT, while the acid fractions were analysed for OTA. The developing solvents for the first and second runs for AFs, OTA, DON, T-2 toxin and PAT were dichloromethane/ethyl acetate/propan-2-ol (90:5:5 v/v/v) and toluene/ethyl acetate/formic acid (6:3:1) respectively. After the second run, the plates for AFs and OTA analysis were dried and visualized under UV radiation at wavelength of $365 \mathrm{~nm}$. TLC plates for trichothecenes and PAT analysis were derivatized with chromotropic acid (Baxter et al. (1983) and 3-methyl-2-benzothiazolinone hydrazone hydrochloride $(0.5 \%)$ in water respectively. The plates for ZEA analysis were run twice in dichloromethane/acetone $(9: 1 \mathrm{v} / \mathrm{v})$ and derivatized with cold dianisidine reagent prepared according to Malaiyandi et al. (1976). Plates for FB analysis were developed in dicholoromethane/methanol/acetic acid $(80: 20: 2 \mathrm{v} / \mathrm{v} / \mathrm{v})$ and butanol/water/acetic acid (12:5:3 v/v/v) respectively. FBs were visualized as purple spots on the dried plates that were sprayed with $p$-anisaldehyde reagent, followed by heating for $3 \mathrm{~min}$ at $120^{\circ} \mathrm{C}$.

High-performance liquid chromatographic analysis of rice sample extracts

AFs, ZEA, OTA, DON, FBs and PAT were quantified in the appropriate fractions of the rice sample extracts by HPLC. AFs $\left(\mathrm{AFB}_{1}, \mathrm{AFB}_{2}, \mathrm{AFG}_{1}\right.$ and $\left.\mathrm{AFG}_{2}\right)$ were individually determined using HPLC with fluorescence detection after post column electrochemical derivatization with bromine using KOBRA cell (Reif and Metzger 1995). The eluent was water/methanol $(58: 42 \mathrm{v} / \mathrm{v})$ with the addition of 119 mg potassium bromide and $100 \mu \mathrm{l}$ nitric acid (65\%) per litre at a flow-rate of $0.8 \mathrm{ml} / \mathrm{min}$ (isocratic). The AFs were detected using a scanning fluorescence detector $\left(\lambda_{\text {ex. }}=\right.$ $360 \mathrm{~nm}, \lambda_{\text {em. }}=440 \mathrm{~nm}$ ).

ZEA was analysed by fluorescent detector at excitation and emission wavelengths of $274 \mathrm{~nm}$ and $418 \mathrm{~nm}$ respectively, in accordance with the method of Abdulkadar et al. (2004). The injection volume was set at $20 \mu \mathrm{l}$, while the mobile phase (acetonitrile/water, 45:55 v/v) was pumped at the flow rate of $1 \mathrm{ml} / \mathrm{min}$. OTA analysis was performed by fluorescence detection as described by Ghali et al. (2009). The mobile phase (acetonitrile/water/acetic acid, 50:48:2 v/v/v) was pumped at a flow rate of $1 \mathrm{ml} / \mathrm{min}$. Respective fluorescence excitation and emission wavelengths of $334 \mathrm{~nm}$ and $460 \mathrm{~nm}$ were used.

Residues for FB analysis were reconstituted in methanol, and aliquots derivatized with $o$-phthaldialdehyde (OPA) prior to separation on a reversed-phase HPLC system using fluorescence detection at excitation and emission wavelengths of 335 and $440 \mathrm{~nm}$ respectively (Shephard et al. 2000). The isocratic mobile phase made up of $0.1 \mathrm{~mol} / 1$ sodium dihydrogen phosphate/methanol (80:20) that had its $\mathrm{pH}$ adjusted to 3.5 using orthophosphoric acid, was pumped at a flow rate of $1 \mathrm{ml} / \mathrm{min}$. The injection volume was $20 \mu \mathrm{l}$. The operating conditions for the determination of PAT by HPLC using the diode array detection method (Moukas et al. 2008) were: the mobile phase, water/ acetonitrile/perchloric acid (990:10:1) injected at a flow rate of $1 \mathrm{ml} / \mathrm{min}$. The injection volume was $50 \mu \mathrm{l}$. The detection of PAT was performed by scanning from 220 to $360 \mathrm{~nm}$ wavelength range. Maximum absorption of PAT was at $276 \mathrm{~nm}$. DON was analysed on a photodiode array detector at $220 \mathrm{~nm}$ according to the method described by Igor et al. (2008). The mobile phase was acetonitrile/water (16:84 v/v) and was pumped at a flow rate of $0.6 \mathrm{ml} / \mathrm{min}$. The injection volume was $20 \mu \mathrm{l}$. Mycotoxins were quantified using retention time, peak area and external calibration curves.

Validation of mycotoxins analytical methods

In addition to using validated methods, internal and external quality control experiments were conducted in order to evaluate the reliability of the extraction, TLC and HPLC results. The typical parameters for validation of methods namely specificity, accuracy, linearity and detection limits as recommended by Araujo (2009) were determined. The limit of detection was estimated by visual determination. Known concentrations of mycotoxin standards were prepared and successively diluted and subjected to TLC and HPLC until the minimum concentration at which the analyte can be detected was established. This was taken as the limit of detection. Rice samples that were shown by TLC not to contain mycotoxins or those with known mycotoxin concentrations were spiked with $100 \mu \mathrm{g} / \mathrm{kg}$ of AFs, OTA, ZEA and PAT for determination of recoveries, a 
spiking levels of $500 \mu \mathrm{g} / \mathrm{kg}$ was used for DON and FBs. Linearity of the HPLC method was checked from correlation coefficients of the calibration curves of the known concentrations of the standards. The $\mathrm{R}_{\mathrm{F}}$ values and retention time of the mycotoxin standards are indicative of the specificity of the methods.

Table 1 provides the typical method validation parameters that were determined in order to ensure the reliability of the methods employed in this work. The chromatographic separation, the low detection limits of both HPLC and TLC, and the recoveries of $69.7-95.6 \%$ for the various mycotoxins indicated that the sensitivity and reliability of the methods employed was sufficient for the purpose of food analysis. All analytical data were subjected to statistical analysis using SigmaStat 3.5 for Windows (Systat, Chicago, Ill., USA).

\section{Results and discussion}

The amount of data concerning mycotoxins in rice from Nigeria was very limited. Except for the work of Makun et al. (2007), who reported the presence of $\mathrm{AFB}_{1}$, ZEA and OTA in mouldy rice, all other studies from this country are restricted to AFs (Ikeorah and Okoye 2005). However, Ayejuyo et al. (2008) assessed and found OTA in imported rice marketed in Lagos metropolis. The present work provides for the first time the mycotoxin profile of rice from Nigeria with respect to seven of the most important mycotoxins worldwide, namely AFs, OTA, ZEA, DON, T-2 toxin, FBs and PAT. Table 2 summarizes the incidence and concentration data of each mycotoxin as identified and quantified using TLC and HPLC respectively. All myco- toxins identified by TLC were quantified using HPLC except for T-2 which for lack of experimental materials was not analysed at HPLC level. The concentration values reported in this study were adjusted based on the recovery rates obtained. The survey has shown AFs, OTA, ZEA, FBs, DON and T-2 toxin as contaminants of rice from Nigeria. The lower detection limit and hence higher sensitivity of HPLC over TLC as shown on Table 1 explains the higher incidence of ZEA (11), DON (five) and $\mathrm{FB}_{1}$ (three) observed with HPLC compared with TLC (six, three and zero, respectively). TLC could not detect ZEA, DON and $\mathrm{FB}_{1}$ at concentrations below $20 \mu \mathrm{g} / \mathrm{kg}$, $100 \mu \mathrm{g} / \mathrm{kg}$, and $50 \mu \mathrm{g} / \mathrm{kg}$ in five, three, and three samples respectively.

High frequencies of AFs (100\%), OTA (66.7\%) and ZEA (53.4\%) were found in this study (Table 2), while the other mycotoxins were found less frequently (DON $23.8 \%$, $\mathrm{FB}_{1} 14.3 \%, \mathrm{FB}_{2} 4.8 \%$ ) or were not found at all ( $\left.\mathrm{FB}_{3}, \mathrm{PAT}\right)$. These results confirm our earlier work (Makun et al. 2007). The mean mycotoxin concentration values observed in the previous study $\left(\mathrm{AFB}_{1}, 200.19 \mu \mathrm{g} / \mathrm{kg}\right.$; ZEA, $207.9 \mu \mathrm{g} / \mathrm{kg}$; OTA, $155.6 \mu \mathrm{g} / \mathrm{kg}$ ) were much higher than those obtained in the present one $\left(\mathrm{AFB}_{1}, 37.9 \mu \mathrm{g} / \mathrm{kg} ; \mathrm{ZEA}, 10.4 \mu \mathrm{g} / \mathrm{kg}\right.$; OTA, $141.9 \mu \mathrm{g} / \mathrm{kg}$ ), the reason being that the former was a biased research where only mouldy rice samples were analysed, in contrast to the later where representative samples were used for analysis. Mouldy samples usually contain higher mycotoxin contents than unmouldy ones (Udoh et al. 2000).

AFs (all four compounds) were found in all samples. It has to be emphasized that all samples had AF levels exceeding acceptable limits $(10 \mu \mathrm{g} / \mathrm{kg})$ set by the 77 countries that regulate AFs, including the European Union

Table 1 Validation method parameters

\begin{tabular}{|c|c|c|c|c|c|c|}
\hline Mycotoxin & $\begin{array}{l}\mathrm{RF}_{1} \& \mathrm{RF}_{2} \text { values } \\
\text { of toxin in TLC }\end{array}$ & $\begin{array}{l}\text { Detection limit } \\
\text { of TLC }(\mu \mathrm{g} / \mathrm{kg})\end{array}$ & $\begin{array}{l}\text { Retention time of } \\
\text { toxin in HPLC } \\
\text { (mins) }\end{array}$ & $\begin{array}{l}\text { Detection limit of } \\
\text { HPLC }(\mu g / \mathrm{kg})\end{array}$ & $\begin{array}{l}\text { Linearity of HPLC } \\
\text { calibration curves }\end{array}$ & $\begin{array}{l}\text { Mean } \pm \mathrm{SD} \text { of } \\
\text { recovery rates } \\
(\%)\end{array}$ \\
\hline $\mathrm{AFB}_{1}$ & $66 \& 31$ & 2.0 & 13.2 & 0.02 & 0.9 & $95.6 \pm 5.8$ \\
\hline $\mathrm{AFB}_{2}$ & $64 \& 26$ & 2.0 & 9.3 & 0.01 & 0.9 & $93.0 \pm 3.7$ \\
\hline $\mathrm{AFG}_{1}$ & $60 \& 18$ & 3.0 & 9.6 & 0.01 & 0.9 & $96.7 \pm 8.0$ \\
\hline $\mathrm{AFG}_{2}$ & $55 \& 18$ & 2.0 & 7.2 & 0.06 & 0.9 & $97.0 \pm 7.1$ \\
\hline OTA & $6 \& 67$ & 5.0 & 11.2 & 0.0002 & 0.9 & $92.8 \pm 2.5$ \\
\hline ZEA & $25 \& 65$ & 20.0 & 13.9 & 16.0 & 0.9 & $91.0 \pm 4.0$ \\
\hline DON & $13 \& 20$ & 100 & 7.9 & 8.0 & 0.9 & $92.0 \pm 12.8$ \\
\hline $\mathrm{FB}_{1}$ & $25 \& 50$ & 50 & 6.0 & 10.0 & 0.9 & $79.1 \pm 11.4$ \\
\hline $\mathrm{FB}_{2}$ & $23 \& 48$ & 50 & 12.0 & 20.0 & 0.9 & $84.0 \pm 3.9$ \\
\hline $\mathrm{FB}_{3}$ & $21 \& 45$ & 100 & 10.8 & 15,0 & 0.9 & $69.7 \pm 9.0$ \\
\hline PAT & $34 \& 56$ & 20 & 10.6 & 5.0 & 0.9 & $89.3 \pm 12.9$ \\
\hline $\mathrm{T}-2$ toxin & $30 \& 40$ & 20 & ND & ND & ND & ND \\
\hline
\end{tabular}

$N D$ not determined 
Table 2 Frequency and concentration data of the major mycotoxins in Nigerian rice from Niger State

\begin{tabular}{lllll}
\hline Mycotoxin & $\begin{array}{l}\text { Number of samples } \\
\text { analysed }\end{array}$ & $\begin{array}{l}\text { Frequency of positive } \\
\text { samples by TLC }\end{array}$ & $\begin{array}{l}\text { Frequency of positive } \\
\text { samples by HPLC }\end{array}$ & $\begin{array}{l}\text { Concentration ( } \mu \mathrm{g} / \mathrm{kg}) \text { in rice } \\
\text { samples as determined by HPLC }\end{array}$ \\
\hline $\mathrm{AFB}_{1}$ & 21 & 21 & 21 & $37.2 \pm 14.0(4.1-309.0)$ \\
$\mathrm{AFB}_{2}$ & 21 & 21 & 21 & $8.3 \pm 1.1(1.3-24.2)$ \\
$\mathrm{AFG}_{1}$ & 21 & 21 & 21 & $22.1 \pm 3.4(5.5-76.8)$ \\
$\mathrm{AFG}_{2}$ & 21 & 19 & 19 & $14.7 \pm 2.5(3.6-44.4)$ \\
Total AFs & 21 & 21 & 21 & $82.5 \pm 16.9(27.7-371.9)$ \\
$\mathrm{OTA}$ & 21 & 14 & 14 & $141.7 \pm 25.4(0-341.3)$ \\
$\mathrm{ZEA}$ & 21 & 6 & 11 & $10.6 \pm 2.8(0-41.9)$ \\
$\mathrm{DON}$ & 21 & 2 & 5 & $18.9 \pm 8.5(0-112.2)$ \\
$\mathrm{FB}$ & 21 & 0 & 3 & $0.2 \pm 0.2(0.4-4.4)$ \\
$\mathrm{FB}$ & 21 & 1 & 1 & $6.0 \pm 6.0(132.5-132.5)$ \\
$\mathrm{FB}$ & 21 & 0 & 0 & - \\
$\mathrm{PAT}$ & 21 & 0 & 0 & - \\
$\mathrm{T}-2$ toxin & 21 & 1 & $\mathrm{NA}$ & $\mathrm{NA}$ \\
\hline
\end{tabular}

$N A$ not analysed

${ }^{\text {a }}$ Concentrations are expressed as mean \pm standard error of mean and range in parentheses

(CAST 2003; EC 2006). OTA was detected in $66.7 \%$ of the rice samples. Like AFs, OTA occurred at very high levels $(134-341 \mu \mathrm{g} / \mathrm{kg}$ ) above the maximum tolerated levels $(2-50 \mu \mathrm{g} / \mathrm{kg})$ set by the aforementioned international regulatory bodies in cereals for human consumption. $\mathrm{ZEA}, \mathrm{FB}_{1}$ and $\mathrm{FB}_{2}$ and DON occurred in $52.4 \%, 14.3 \%$ and $23.8 \%$ of the rice samples respectively and were found at levels accepted by mycotoxin regulatory agencies. The acceptable limits for ZEA, FBs and DON are $30-200 \mu \mathrm{g} / \mathrm{kg}$, $<1,000 \mu \mathrm{g} / \mathrm{kg}$ and $750-2,000 \mu \mathrm{g} / \mathrm{kg}$ respectively (CAST 2003; EC 2006). This evaluation of mycotoxins in Nigerian rice gives the quality of the cereal with regards to its acceptability for human and animal consumption. The demonstrated presence of AFs and OTA at concentrations above the limits acceptable to world mycotoxin regulatory agencies and the co-occurrences of toxins with possible toxic synergistic effects make this studied rice sample of low quality for human and animal consumption and in fact raises preliminarily national public health concerns.

Although the levels of AF contamination found in this study in rice for human consumption (up to $372 \mu \mathrm{g} / \mathrm{kg}$ ) are lower than the levels $(1,600-12,000 \mu \mathrm{g} / \mathrm{kg})$ that caused deaths in the two fatal outbreaks of AF poisoning in Kenya (Afla-Guard 2005), chronic intake of such toxin levels could synergically work with other carcinogens, especially hepatitis B virus, to elicit the high primary liver cancer incidence observed in Nigeria (Olubuyide and Solanke 1990). Continuous intake of small doses of AFs could increase still-births and neonatal mortality, immunosuppression with increased susceptibly to infectious diseases such as pneumonia, stunting of growth (Bankole and Adebanjo 2003) and HIV/AIDS (Lane 2005).
However, in terms of overall concentration, OTA was the predominant mycotoxin in the rice samples. OTA contamination of cocoa and cocoa products in Nigeria has been documented (Bankole and Adebanjo 2003) but very few reports of its incidence in other crops from the country are available. A high level of $150 \mu \mathrm{g} / \mathrm{kg}$ of the toxin was detected in maize (Sibanda et al. 1997) and mouldy rice (Makun et al. 2007) from northern Nigeria. Ayejuyo et al. (2008) found very low levels of OTA $(0.0-2.1 \mu \mathrm{g} / \mathrm{kg})$ in 25 brands of imported rice marketed in Lagos metropolis. The OTA contents in imported rice were all above the international regulatory limit of $5 \mu \mathrm{g} / \mathrm{kg}$, and levels in the present study $(133.8-305.5 \mu \mathrm{g} / \mathrm{kg}$ ), and this is because there must have been compliance to the international regulatory limits at the point of processing, packaging and import. The almost $70 \%$ frequency of this nephrotoxin at unacceptable amounts in Nigerian-grown rice and maize, which are within the lower limits of OTA concentrations $(200-1,000 \mu \mathrm{g} / \mathrm{kg})$ that caused mycotoxic porcine nephropathy in Bulgaria (Stoev et al. 2002), could with other factors, such as malaria, hypertension and diabetes, cause the rising incidences of chronic renal diseases experienced presently in Nigeria as well as animal nephropathy. The lack of renal registry in Nigeria makes the computation of chronic renal disease data difficult; however, available hospital data revealed that chronic renal failure (CRF) accounts for about $10 \%$ of medical admissions in Nigeria and an extrapolation of this puts the frequency figure between 200 and 300 patients per million of population (NAN 2008).

While contamination of Nigerian feeds and foods by ZEA (Makun et al. 2007), DON (Adejumo et al. (2007) and 
FBs (Bankole et al. 2003) has been reported by several authors, the present study seems to be the first one reporting the occurrence of DON and FBs in rice from Nigeria. ZEA, DON and FBs levels in our rice samples were all below common maximum levels, including the European Union acceptable limit. However, the frequent occurrence of these toxins in rice, which is commonly regarded as a major source of intake of Fusarium toxins, should be taken seriously.

The differences in frequency of occurrence and concentrations of the studied mycotoxins with respect to the types of rice sampled (i.e. field, stored and market samples) was also determined and the data presented in Table 3. Although there was no consistent trend, i.e. decrease or increase in mycotoxin incidence and concentrations from field to market, it must also be noted that the market samples were less frequently contaminated with some toxins, and had lower toxin levels than the field and store samples, in particular concerning Fusarium toxins. In contrast, little differences were found for AFs and OTA. Traditional rice farmers grow rice as a source of income (Erenstein and Lancon 2003), so products for the market undergo a second sun drying, winnowing and handpicking of physically damaged and infected grains in order to upgrade the produce. These processes significantly reduce the fungal and mycotoxin contamination (Hell et al. 2000) and might therefore account for the consistently lower incidence and mycotoxin contents of the market samples compared with the field and stored grains.
Co-occurrence of mycotoxins was a common phenomenon in rice from Niger State. The mycotoxin profile shows that the mycotoxin contaminants did not occur singly but in combinations of twos, threes, fours and fives. Dual co-contamination with two types of mycotoxins occurred in a few samples only, with AFs and OTA only found in three samples, and each sample had AFs/ZEA or $\mathrm{AFs} / \mathrm{FB}_{1}$. Simultaneous contamination with three mycotoxins in one sample was found for AFs/OTA/ZEA (four samples) and AFs/OTA/DON (two samples). Two samples each were co-contaminated by four types of mycotoxins (AFs/OTA/ZEA/FB 1 or $\mathrm{AFs} / \mathrm{OTA} / \mathrm{ZEA} / \mathrm{DON}$ ), while one sample contained the combinations $\mathrm{AFs} / \mathrm{OTA} / \mathrm{ZEA} / \mathrm{FB}_{2}$ and $\mathrm{AFs} / \mathrm{OTA} / \mathrm{ZEA} / \mathrm{T}-2$ toxin. One sample contained five types of mycotoxins (AFs/OTA/ZEA/FB $1 / \mathrm{DON}$ ) simultaneously.

The implications of such toxin "cocktails" on human health are presently unknown. However, the interactive effects of mycotoxins in these natural combinations could be synergistic, additive or antagonistic in host organisms (Miller 1995). Interaction between $\mathrm{AFB}_{1}$ and $\mathrm{FB}_{1}$, which is one of the combinations observed, had an additive effect in mice, causing increased injuries to liver and kidneys of the experimental animals (Gelderblom et al. (2002). Other combinations which were observed in the work and have been demonstrated by other workers to exhibit synergistic interactions include $\mathrm{AFB}_{1}$ and the trichothecenes (Placinta et al. 1999), $\mathrm{FB}_{1}$ and OTA (Creppy et al. 2004), and $\mathrm{FB}_{1}$ and ZEA (Luongo et al. 2008). The simultaneous exposure of OTA and $\mathrm{AFB}_{1}$ to rabbits demonstrated an antagonistic

Table 3 Frequency and concentrations of mycotoxins in different types of rice samples from Niger State. Concentrations are expressed as the mean \pm standard error of the mean, with the range in parentheses

\begin{tabular}{|c|c|c|c|c|c|c|}
\hline \multirow[t]{2}{*}{ Mycotoxins } & \multicolumn{2}{|c|}{ Field samples $(n=10)$} & \multicolumn{2}{|c|}{ Stored samples $(n=6)$} & \multicolumn{2}{|c|}{ Market samples $(n=5)$} \\
\hline & $\begin{array}{l}\text { No. of } \\
\text { positive } \\
\text { samples }\end{array}$ & $\begin{array}{l}\text { Concentration } \\
(\mu \mathrm{g} / \mathrm{kg})\end{array}$ & $\begin{array}{l}\text { No. of positive } \\
\text { samples }\end{array}$ & $\begin{array}{l}\text { Concentrations } \\
(\mu \mathrm{g} / \mathrm{kg})\end{array}$ & $\begin{array}{l}\text { No. of } \\
\text { positive } \\
\text { samples }\end{array}$ & $\begin{array}{l}\text { Concentration } \\
(\mu \mathrm{g} / \mathrm{kg})\end{array}$ \\
\hline $\mathrm{AFB}_{1}$ & 10 & $60.3 \pm 28.2(4.0-304.4)$ & 6 & $12.2 \pm 1.9(5.6-17.6)$ & 5 & $21.0 \pm 4.7(9.9-34.1)$ \\
\hline $\mathrm{AFB}_{2}$ & 10 & $10.0 \pm 2.1(1.3-22.8)$ & 6 & $7.7 \pm 1.4(3.7-13.1)$ & 5 & $5.4 \pm 1.5(2.5-11.2)$ \\
\hline $\mathrm{AFG}_{1}$ & 10 & $33.2 \pm 6.3(8.4-76.8)^{\mathrm{a}}$ & 6 & $13.9 \pm 1.5(7.7-17.4)$ & 5 & $9.5 \pm 1.6(5.5-15.6)^{\mathrm{a}}$ \\
\hline $\mathrm{AFG}_{2}$ & 10 & $17.9 \pm 3.9(3.6-44.4)$ & 6 & $16.5 \pm 4.5(4.4-36.5)$ & 5 & $6.0 \pm 2.5(8.7-12.2)$ \\
\hline Total AFs & 10 & $121.8 \pm 31.5(27.7-371.9)^{\mathrm{b}, \mathrm{c}}$ & 6 & $50.5 \pm 6.4(28.4-72.2)^{\mathrm{b}}$ & 5 & $42.0 \pm 2.9(30.8-47.7)^{\mathrm{c}}$ \\
\hline OTA & 7 & $122.0 \pm 30.8(133.8-305.5)^{\mathrm{d}}$ & 6 & $261.4 \pm 22.0(207.7341 .3)^{\mathrm{d}, \mathrm{e}}$ & 1 & $37.6 \pm 37.6(188.2-188.2)^{\mathrm{e}}$ \\
\hline ZEA & 6 & $14.9 \pm 4.8(11.5-41.9)$ & 4 & $9.9 \pm 4.7(11.8-24)$. & 1 & $1.7 \pm 1.7(8.8-8.8)$ \\
\hline DON & 1 & $107 \pm 10.7(107.9-107.9)$ & 4 & $51.5 \pm 21.6(11.2-112.2)$ & 0 & - \\
\hline $\mathrm{FB}_{1}$ & 1 & $0.1 \pm 0.1(1.0-1.0)$ & 2 & $0.8 \pm 0.72(0.4-4.4)$ & 0 & - \\
\hline $\mathrm{FB}_{2}$ & 1 & $13.2 \pm 13.2(132.5-132.5)$ & 0 & - & 0 & - \\
\hline $\mathrm{FB}_{3}$ & 0 & - & 0 & - & 0 & - \\
\hline PAT & 0 & - & 0 & - & 0 & - \\
\hline $\mathrm{T}-2$ toxin & & NA & & NA & & NA \\
\hline
\end{tabular}

$N A$ not analysed

${ }^{\text {a-d }}$ Values with the same superscripts are significantly different at $P \leq 0.05$ 
interaction between the toxins with regards to teratogenic effects (Wangikar et al. 2005). The complex and varied nature of the effects of mixed mycotoxins is obvious in the synergistic and additive growth depression effects of DON and $\mathrm{FB}_{1}$ in pigs and broiler chicks respectively (Placinta et al. 1999). DON is antagonistic to T-2 in the inhibition of human lymphocytes proliferation (Speijer and Speijer 2004). The interaction data between four or more mycotoxin species, a recurring feature in the rice samples, are virtually unavailable; however, Speijer and Speijer (2004) postulated that combined exposure to several classes of mycotoxins generally results in an additive effect with a few minor exceptions, indicating synergistic interaction.

A comparison of the mycotoxins profile (quality) of rice from Nigeria and those from major rice exporting countries of South East Asia (Thailand, Philippines, Vietnam, Taiwan, Nepal, Sri Lanka, Bangladesh and Indonesia and Nepal) would provide importing countries with the necessary information to make better choices. This pilot study and others works show that AFs, OTA, ZEA, trichothecenes and FBs are rice toxins found in Nigeria (Makun et al. 2007 and Ayejuyo et al. 2008) and are also indigenous to rice exporting countries of South East Asia (Reddy et al. 2008). The fundamental difference between rice from the two areas is the presence of Pencillium toxins; PAT, rubratoxins and the yellow rice disease mycotoxins (citreoviridin, luteoskyrin, cyclochlorotine and citrinin) in SE Asian rice (Smith and Moss 1985) have not yet been demonstrated in Nigerian rice. PAT was not found in our rice samples. The near absence of Penicillium toxins in Nigerian rice is supported by the findings of an unpublished work conducted in our laboratory (Food, Environment and Health Research Group, University of Johannesburg). The study showed that out of 357 fungal species isolated from Nigeria-grown rice only four were Penicllium oxalicum, indicating that Penicillium fungi and their mycotoxins are not a problem in rice from Nigeria. The quality of raw Nigerian rice is therefore likely to be better than those from the SE Asian countries.

\section{Conclusion}

In conclusion, although the number of rice samples analysed in this study was limited, the high frequency of mycotoxins, and the high levels of AFs and OTA in particular found in these samples, clearly shows the necessity for increased surveillance. Much more rice samples from different points of processing from around the country should be analysed. At the moment, our results obtained in this pilot work indicated that because of high $\mathrm{AF}$ and OTA contamination, a considerable percentage of the rice from the Nigerian market could be regarded as unsafe for human consumption. In view of the forgoing, it is also recommended that studies to elucidate the possible aetiologic roles of AFs and OTA in the increased incidences of liver cancer and nephropathy should be conducted in Nigeria. Finally, the findings also show that regulations concerning maximum levels of mycotoxins in foods in Nigeria are urgently needed.

Acknowledgements The authors acknowledge the University of Johannesburg and National Research Foundation of South Africa for funding this study. The rural farmers of Niger State that donated some of the rice samples are duly acknowledged.

Open Access This article is distributed under the terms of the Creative Commons Attribution Noncommercial License which permits any noncommercial use, distribution, and reproduction in any medium, provided the original author(s) and source are credited.

\section{References}

Abdulkadar AHW, Al-Ali AA, Al-Kildi M, Al-Jedah JH (2004) Mycotoxins in food products available in Qatar. Food Control 15:543-548

Adejumo TO, Hettwer U, Karlovsky (2007) Occurrence of Fusarium species and trichothecenes in Nigerian maize. Int $\mathrm{J}$ Food Microbiol 116:350-357

Afla-Guard (2005) Aflatoxin in Africa. www.circleoneglobal.com/ aflatoxin africa.htm

Araujo P (2009) Key aspects of analytical method validation and linearity evaluation. J Chromatogr B 877:2224-2234

Ayejuyo OO, Williams AB, Imafidon TF (2008) OTA burdens in rice from Lagos markets, Nigeria. J Environ Sci Technol 2(1):80-84

Bankole SA, Adebanjo A (2003) Mycotoxins in food in West Africa: current situation and possibilities of controlling it. Afr J Biotechnol 2:254-263

Bankole SA, Mabekoje OO, Enikuomehin OA (2003) Fusarium moniliforme and $\mathrm{FBs}_{1}$ in stored maize from Ogun State, Niger. Trop Sci 43:76-79

Baxter JA, Terhume SJ, Qureshi SA (1983) Use of chromotropic acid for improved thin-layer chromatographic visualization of trichothecenes mycotoxins. J Chromatogr 261:130-133

Bhat RV, Vasanthi S (2003) Mycotoxin food safety risks in developing countries. Food Safety in Food Security and Food Trade. Vision 2020 for Food, Agriculture and Environment, Focus 10, Brief 3, pp 1-2 http://ideas.repec.org/p/fpr/2020br/1003.html

CAST (2003) Mycotoxins: risks in plant, animal, and human systems. Task Force Report No. 139, Council for Agricultural Science and Technology, Ames

CDC (2004) Outbreak of aflatoxin poisoning-Eastern and Central provinces, Kenya, January-July, 2004. Centers for Disease Control and Prevention, Atlanta. http://www.cdc.gov/mmwr/ preview/mmwrhtml/mm5334a4.htm.

Chu FS, Li GY (1994) Simultaneous occurrence of FBs B1 and other mycotoxins in moldy corn collected from the People's Republic of China in regions with high incidences of esophageal cancer. Appl Environ Microbiol 60:847-852

Creppy EE, Chiarappa P, Baudrimont I, Borracci P, Moukha S, Carratu MR (2004) Synergistic effect of FBs B1 and OTA: are in vitro cytotoxicity data predictive of in vivo acute toxicity? Toxicology 201:115-123

Dutton MF (1996) FBs, mycotoxins of increasing importance: their nature and their effects. Pharmacol Ther 70(2):137-161 
EC (2006) Commission Regulation (EC) No 1881/2006 of 19 December 2006 Setting maximum levels for certain contaminants in foodstuffs (text with EEA relevance). Off J Eur Union 364:524

Erenstein O, Lancon F (2003) The Nigerian rice economy in a competitive world. Constraints, opportunities and strategic choices. Report of the final technical workshop held in IITA on August 2021, 2003. Available at http://www.usaid.gov/ng/downloads/markets/ rice_report_of_the_final_technical_workshop.pdf \#5

Ezedinma C (2005) Impact of trade on domestic rice production and the challenge of self-sufficiency in Nigeria. Report presented at the workshop on rice policy and food security in Sub Saharan Africa at Cotonou, Benin on the 7-9th November, 2005. Available at http://www.warda.org/workshop/RicePolicy/Chuma. E/Chuma.E.Nigeria.Paper.pdf

FAO (2002) Proceedings of the 20th session of the International Rice Commission in Bangkok. Corporate Document Repository, Food and Agriculture Organization of the United Nations, Rome

FAO (2008) Paddy rice production (000 t), by country and geographical region: 1961-2007. Statistics Division, Food and Agriculture Organization of the United Nations, Rome. Available at http://beta.irri.org/ solutions/images/stories/wrs/wrs_nov08_table01_production.xls

Gelderblom WCA, Marasas WFO, Lebepe-Mazur S, Swanevelder S, Vessey CJ, Hall P de la M (2002) Interaction of FBs $B_{1}$ and aflatoxin $\mathrm{B}_{1}$ in a short term carcinogenesis model in rat liver. Toxicology 171:161-173

Ghali R, Hmaissia-Khlifa K, Ghorbel H, Maaroufi K, Hedilli A (2009) HPLC determination of OTA in high consumption Tunisian foods. Food Control 20:716-720

Hell K, Cardwell KF, Setamou M, Poehling HM (2000) The influence of storage practices on aflatoxin contamination in maize in four agroecological zones of Benin, West Africa. J Stored Prod Res 36:365-382

Hendricks K (1999) FBs and neural tube defects in South Texas. Epidemiology 10:198-200

Hussein SH, Brasel JM (2001) Toxicity, metabolism and impact of mycotoxins on humans and animals. Toxicology 167:101-134

Igor J, Vuric V, Abramovic B (2008) First survey of DON occurrence in crops in Serbia. Food Control 19:545-550

Ikeorah J, Okoye ZS (2005) Four decades of research on AFs in Nigeria: a review of NSPRI experience. Regional Workshop on Mycotoxins organized by National Agency for Food and Drug Administration and Control (NAFDAC) in collaboration with International Atomic Energy Agency (IAEA), Victoria Garden City, Lagos, Nigeria, 7th-11th February, 2005

Lane KS (2005) New support for FDA regulation of tobacco. Available at www.Tobacco.org

Luongo D, De Luna RD, Russo R, Severino L (2008) Effects of four Fusarium toxins (FBs B1, $\alpha$-zearalenol, nivalenol and DON) on porcine whole-blood cellular proliferation. Toxicon 52:156-162

Makun HA, Gbodi TA, Akanya HO, Sakalo AE, Ogbadu HG (2007) Fungi and some mycotoxins contaminating rice (Oryza sativa) in Niger state, Nigeria. Afr J Biotechnol 6(2):99-108

Makun HA, Gbodi TA, Akanya HO, Salako EA, Ogbadu GH (2009) Fungi and some mycotoxins found in mouldy Sorghum in Niger State, Nigeria. World J Agri Sci 5(1):5-17

Malaiyandi M, Barrette JP, Wavrock PL (1976) Bis-diazotised 652 benzidine as a spray reagent for detecting ZEA on thin layer chromatography. J Assoc Off Anal Chem 59:959-962

Miller JD (1995) Fungi and mycotoxins in grains: implications for stored product research. J Stored Prod Res 31(1):1-16
Moukas A, Panagiotopoulou V, Panagiota M (2008) Determination of PAT in fruit juices using HPLC-DAD and GC-MSD techniques. Food Chem 109:860-867

NAN (2008) Nigerian Association of Nephrology. www.nanephrology.org/

Olubuyide IO, Solanke TF (1990) The causes of death in an elderly African population. J Trop Med Hyg 93:270-274

Patterson DSP, Roberts BA (1979) Mycotoxins in animal feedstuffs: sensitive thin layer chromatographic detection of aflatoxin, OTA, sterigmatocystin, ZEA and T2 toxin. J Assoc Off Anal Chem 62:1265-1267

Placinta CM, D'Mello JPF, Macdonald AMC (1999) A review of worldwide contamination of cereal grains and animal feed with Fusarium mycotoxins. Anim Feed Sci Technol 78:21-37

Reddy KRN, Reddy CS, Abbas HK, Abel CA, Muralidharan K (2008) Mycotoxigenic fungi, mycotoxins and management of rice grains. Toxin Rev 27:287-317

Reif K, Metzger W (1995) Determination of AFs in medicinal herbs and plant extracts. J Chromatogr A 692:131-136

Rheeder JP, Marasas WFO, Thiel PG, Sydenham EW, Shephard GS, Van Schalkwyk DJ (1992) Fusarium moniliforme and FBs in corn in relation to human oesophageal cancer in Transkei. Phytopathology 82:353-357

Shephard GS (2008) Impact of mycotoxins on human health in developing countries. Food Addit Contam 25(2):146-151

Shephard GS, Marasas WFO, Leggott NL, Yazdanpanah H, Rahimian H, Safavi N (2000) Natural occurrence of FBs in corn from Iran. J Agric Food Chem 48:1860-1864

Sibanda L, Marovatsanga LT, Pestka JJ (1997) Review of mycotoxin work in sub-Saharan Africa. Food Control 8:21-29

Smith JE, Moss MO (1985) Mycotoxins: formation, analysis and significance. Wiley, Chichester, pp 1-143

Speijer GJA, Speijer MHM (2004) Combined toxic effects of mycotoxins. Toxicol Lett 153:91-98

Stoev SD, Paskalev M, MacDonald S, Mantle PG (2002) Experimental one year OTA toxicosis in pigs. Exp Toxicol Pathol 53:481-487

Sudakin DL (2003) Trichothecenes in the environment: relevance to human health. Toxicol Lett 143:97-107

Sydenham EW, Thiel PG, Marasas WFO, Shephard GS, Van Schalkwyk DJ, Koch KR (1990) Natural occurrence of some Fusarium mycotoxins in corn from low and high esophageal cancer prevalencefrequency areas of the Transkei, Southern Africa. J Agr Food Chem 38:1900-1903

Sydenham EW, Shephard GS, Thiel PG (1992) Liquid chromatographic determination of fumosins $\mathrm{B}_{1}, \mathrm{~B}_{2}$, and $\mathrm{B}_{3}$ in foods and feeds. J Assoc Off Anal Chem 75:313-318

Udoh JM, Cardwel KF, Ikotun T (2000) Storage structures and aflatoxin content of maize in five agro-ecological zones of Nigeria. J Stored Prod Res 36:187-201

USDA (2008a) Import of milled rice by country and geographical region: 1961-2008. Available at http://beta.irri.org/solutions/ images/stories/wrs/wrs_jul08_2009_table10_usda_import.xls.

USDA (2008b) Rice consumption by country and geographical region. Available at http://beta.irri.org/solutions/images/stories/ wrs/wrs jul30_2009 table17_consumption_USDA.xls

Wangikar PB, Dwivedi P, Sinha N, Sharma AK, Telang AG (2005) Teratogenic effects in rabbits of the simultaneous exposure to OTA and aflatoxin B1 with special reference to microscopic effects. Toxicology 215:37-47

Zinedine A, Soriano JM, Molto JC, Manes J (2007) Review on the toxicity, occurrence, metabolism, detoxification, regulations and intake of ZEA: an oestrogenic mycotoxin. Food Chem Toxicol 45:1-18 